\title{
Associations of self-reported atopic dermatitis with comorbid conditions in adults: a population-based cross-sectional study
}

Jevgenija Smirnova ${ }^{1,2^{*}}$, Scott Montgomery ${ }^{1,3,4}$, Magnus Lindberg ${ }^{1,5}$, Åke Svensson ${ }^{6}$ and Laura von Kobyletzki ${ }^{1,6,7}$

\begin{abstract}
Background: The objective of this study was to investigate the relationships between atopic dermatitis (AD) and other common chronic health conditions in adults.

Methods: A cross-sectional survey was sent to a randomly selected population sample of 78,004 adults in Sweden. The questionnaires included measures of self-reported physical and mental health. Binary and multinomial logistic regression were used to examine the associations of $A D$ with common chronic health conditions and psychological wellbeing.

Results: AD was self-reported by 4,175 respondents, representing almost 14\% of the study population of 34,313 adults. Our results showed positive associations between $A D$ and chronic health disorders, including conditions of the oral cavity: chronic obstructive pulmonary disease (adjusted odds ratio [aOR] $=1.58,95 \%$ confidence interval [Cl]: 1.30 to 1.92), asthma (aOR $=2.13,95 \% \mathrm{Cl}: 1.91$ to 2.38), mild recurrent gastrointestinal symptoms (adjusted relative risk ratio $[\mathrm{aRRR}]=1.78,95 \% \mathrm{Cl}: 1.64$ to 1.92$)$, high blood pressure $(\mathrm{aOR}=1.16,95 \% \mathrm{Cl}: 1.06$ to 1.26$)$, obesity $(\mathrm{aOR}=1.34,95 \% \mathrm{Cl}: 1.23$ to 1.47$)$, mild joint pain ( $\mathrm{RRRR}=1.47,95 \% \mathrm{Cl}: 1.35$ to 1.61 ), mild headache or migraine ( $a R R R=1.50,95 \% \mathrm{Cl}: 1.38$ to 1.64 ), caries ( $\mathrm{aOR}=1.25,95 \% \mathrm{Cl}: 1.04$ to 1.49$)$, bleeding gums (aOR $=1.69,95 \% \mathrm{Cl}: 1.38$ to 2.08 ), periodontitis ( $a \mathrm{OR}=1.42,95 \% \mathrm{Cl}: 1.13$ to 1.77 ), sensitive teeth ( $\mathrm{aOR}=1.57,95 \% \mathrm{Cl}: 1.35$ to 1.82 ), and dry mouth (aOR $=1.52,95 \% \mathrm{Cl}: 1.33$ to 1.74). Adjustment for asthma and depression attenuated the magnitude of the associations between $\mathrm{AD}$ and the study outcomes. AD was also associated with poorer general psychological wellbeing.
\end{abstract}

Conclusions: Adults reporting AD may be at increased risk of chronic disorders and decreased psychological wellbeing. Physicians should recognize that individuals with severe AD and those with comorbid asthma or depression may be especially vulnerable.

Keywords: Atopic dermatitis, epidemiology, comorbidity, oral health, diabetes mellitus, hypertension, obesity

\footnotetext{
* Correspondence: jevgenija.smirnova@oru.se

${ }^{1}$ School of Medical Sciences, Örebro University, Campus USÖ, S-701 82

Örebro, Sweden

${ }^{2}$ Department of Dermatology, Karlstad Central Hospital, Karlstad, Sweden

Full list of author information is available at the end of the article
}

(c) The Author(s). 2020 Open Access This article is licensed under a Creative Commons Attribution 4.0 International License, which permits use, sharing, adaptation, distribution and reproduction in any medium or format, as long as you give appropriate credit to the original author(s) and the source, provide a link to the Creative Commons licence, and indicate if changes were made. The images or other third party material in this article are included in the article's Creative Commons. licence, unless indicated otherwise in a credit line to the material. If material is not included in the article's Creative Commons licence and your intended use is not permitted by statutory regulation or exceeds the permitted use, you will need to obtain permission directly from the copyright holder. To view a copy of this licence, visit http://creativecommons.org/licenses/by/4.0/. The Creative Commons Public Domain Dedication waiver (http://creativecommons.org/publicdomain/zero/1.0/) applies to the data made available in this article, unless otherwise stated in a credit line to the data. 


\section{Background}

Atopic dermatitis (AD) is a chronic inflammatory skin disease common in children and adults, with a lifetime prevalence of about $10-20 \%$ [1]. This itchy skin disease, which may have a negative impact on the quality of life of people with the disease and their families, accounts for the largest global health burden caused by a skin disease $[2,3]$. Health and quality of life may be especially impaired for individuals with concomitant mental health and atopic conditions $[3,4]$. There is increasing evidence of the co-occurrence of common chronic diseases in individuals with $\mathrm{AD}[5]$.

Previous studies have reported associations between $\mathrm{AD}$ and both rheumatoid arthritis and inflammatory bowel disease [6]. Asthma has also been linked to AD, but, to the best of our knowledge, no studies have assessed the possible association between $\mathrm{AD}$ and chronic obstructive pulmonary disease (COPD), which also affects the epithelial tissues of the airways. Further, smoking has been reported to be associated with both $\mathrm{AD}$ and $\mathrm{COPD}$, suggesting that it may be a shared risk factor for the two diseases. Co-occurrence of migraine has also been observed in individuals with $\mathrm{AD}[7,8]$.

There are conflicting reports regarding the associations of $\mathrm{AD}$ with cardiovascular and metabolic disorders. In a recent meta-analysis, no statistically significant associations were found between $\mathrm{AD}$ and either hypertension or type 2 diabetes [9]. However, the studies included in the meta-analysis defined AD in various ways, and most included no information on the severity of AD [9]. Some previous observations of associations of $\mathrm{AD}$ with hypertension and type 2 diabetes may be explained by shared risk factors such as smoking and obesity [9-11].

Inflammatory diseases frequently involve conditions of the oral cavity, but few studies have investigated possible associations of AD with disorders of the oral cavity [12]. One national cross-sectional study conducted in the United States showed that children with severe AD had a higher prevalence of both toothache and bleeding gums [13]. To the best of our knowledge, no studies of adults with $\mathrm{AD}$ have examined the possibility of impaired health of the oral cavity.

The objective of this study was to examine the associations between self-reported $\mathrm{AD}$ and common chronic health conditions in adults sampled from the general population in Sweden.

\section{Methods}

This study used data from Life and Health (Liv och Hälsa), a population survey conducted from March to June 2017 in Sweden. A postal questionnaire was distributed to a randomly selected population-based sample of 78,004 adults in five Swedish counties (Södermanland, Uppsala, Värmland, Västmanland, and Örebro), stratified by sex, age, and municipality. The questionnaire covered many topics, including health conditions, living habits, socioeconomic characteristics such as level of education, and questions derived from the 5-item World Health Organization Well-Being Index (WHO-5). The questionnaire included core questions for all study participants and additional questions specifically for the age groups of 18-29 years, 30-69 years, and 70 years and older. The response rate was $44 \%$. Non-responders tended to be younger, men, people with lower levels of education, and individuals born in non-Nordic countries. The Life and Health study, including the methods of data collection and non-response analysis, have been described elsewhere [14]. The questionnaires used in the study are available on the municipality website [15].

Written informed consent was obtained from all participants. Ethical approval for this study was obtained from the Uppsala Regional Ethics Committee (registration number: 2015/417).

\section{Variables}

The study measures were self-reported, and they were assessed using validated questions, whenever possible, or questions that have been used repeatedly in national and international surveys. The question used to assess $\mathrm{AD}$ was: 'Do you have any of the following conditions?', with 'eczema' as one of the listed conditions. This item had three response options: no; yes, mild symptoms; and yes, severe symptoms. Through discussion, a group of physicians, epidemiologists, and laypeople judged the face and content validity of this item as high. The AD question was also tested with 14 individuals with and without $\mathrm{AD}$. The term 'eczema' was considered to be understandable by the general population in Sweden.

The health outcome variables used in this study were measured using the following question stem: 'Do you have the following physician-diagnosed conditions?'. For the listed conditions of 'asthma', 'COPD', 'high blood pressure', 'type 2 diabetes', and 'depression', respondents chose between the responses of yes and no. For 'gastrointestinal symptoms', 'joint pain', and 'headache or migraine', three response options were: no disease; yes, mild symptoms; and yes, severe symptoms. Joint pain was defined as pain in one or several of the following locations: shoulders, neck, back, arms, elbows, legs, and knees. The items for COPD, high blood pressure, and type 2 diabetes were not included in the questionnaire for those aged under 30 years. Obesity was defined as a body mass index (BMI) of 30 or greater, calculated using questionnaire-reported weight and height. General subjective psychological wellbeing was estimated using the WHO-5 questions, and scores over 75 were interpreted as very good psychological wellbeing. 
A detailed battery of questions on conditions of the oral cavity was included in the questionnaire for those aged 70 years and over, with items on caries, bleeding gums, periodontitis, sensitive teeth, and dry mouth. These conditions of the oral cavity were assessed using the question stem 'Do you have any of the following conditions?', with a binary answer option of yes or no for each condition.

Characteristics included in this study as potential confounding factors were sex, age group (18-29, 30-69, and $\geq 70$ years), and smoking (no; yes, daily or occasionally). Respondents' level of education (compulsory schooling, secondary, or higher education) was assessed using linked data from Statistics Sweden.

\section{Statistical analysis}

Cross-tabulation was used to describe the study population. The associations between AD and the study outcomes were examined using binary logistic regression for the outcomes with two response categories (no, yes) and multinomial logistic regression for the outcomes with three response categories (no; yes, mild symptoms; yes, severe symptoms). Binary logistic regression produces odds ratios (ORs), whereas multinomial logistic regression compares each outcome category with a reference category and produces a relative risk ratio (RRR). All regression models were adjusted for sex, age group, smoking, and education level. The models for the associations of $\mathrm{AD}$ with conditions of the oral cavity were additionally adjusted for self-reported presence of permanent teeth. We re-estimated the models with additional adjustment for self-reported physician-diagnosed depression to evaluate the possible confounding effects of comorbid depression in individuals with AD.

We also assessed if the associations between the study outcomes and $\mathrm{AD}$ varied by presence of comorbid asthma. A new variable was created with three values: respondents who did not reported $\mathrm{AD}$; respondents who reported having $\mathrm{AD}$ but not asthma; respondents who reported having both $\mathrm{AD}$ and asthma. Logistic regression analyses for associations between the study outcomes and the new variable were adjusted as described for the main analyses.

The association of AD with very good psychological wellbeing was estimated using logistic regression. The odds of having very good psychological wellbeing was assessed for mild and severe $\mathrm{AD}$, and we compared these odds with the same odds for a comparison population of respondents who reported having diabetes, following an approach that has been used in a previous study [16].

The Bonferroni correction was applied to correct for multiple testing. Stratification by age and sex was performed.
Participants with missing values for the adjustment variables (sex, age group, smoking, and education level) were excluded from the analysis. A $p$-value lower than 0.05 , or a $95 \%$ confidence interval $(\mathrm{CI})$ that did not include 1.00, was used to indicate statistical significance. The analysis was conducted using SPSS version 26 statistical software (IBM Corp., 2019).

\section{Results}

The study population consisted of 34,313 respondents (Table 1), 33,516 (43\% of the target population) of that had complete questionnaire data after excluding those with missing data for the adjustment variables. There was a slight but statistically significant predominance of women, who comprised $54 \%$ of the sample. The median age of the respondents was 62 years. The highest level of educational attainment was compulsory schooling for $25 \%$ of the study population, secondary education for $43 \%$, and higher education for $32 \%$. AD was reported by 4,175 respondents (13.9\% of the study population), including 419 respondents who reported severe AD. AD was most common in women aged $18-30$ years. In this age group, $15.5 \%$ reported mild $\mathrm{AD}$, and $3.5 \%$ reported severe AD.

\section{Chronic health conditions}

The self-reported prevalence of common chronic health conditions and their distributions in the study population with no $\mathrm{AD}$, mild $\mathrm{AD}$, and severe $\mathrm{AD}$ are presented in Table 1. All chronic health conditions examined in the current study except type 2 diabetes were more prevalent in individuals with mild AD than in those without AD (Table 2). The association between type 2 diabetes and mild $\mathrm{AD}$ did not reach statistical significance (adjusted OR $[\mathrm{aOR}]=1.11,95 \%$ CI: 0.97 to 1.28). However, individuals with severe AD had statistically significantly higher odds of having type 2 diabetes (aOR $=1.96,95 \%$ CI: 1.37 to 2.79 ) compared with those without AD.

A dose-dependent relationship between severity of health conditions and mild $\mathrm{AD}$ was seen: mild recurrent gastrointestinal symptoms (adjusted RRR [aRRR $=1.78$, 95\% CI: 1.64 to 1.92 ), severe recurrent gastrointestinal symptoms ( $\mathrm{aRRR}=1.85,95 \% \mathrm{CI}$ : 1.58 to 2.17 ), mild joint pain $(\mathrm{aRRR}=1.47,95 \% \mathrm{CI}: 1.35$ to 1.61$)$, severe joint pain $(\mathrm{aRRR}=1.91,95 \% \mathrm{CI}: 1.70$ to 2.14$)$, and mild headache or migraine ( $\mathrm{aRRR}=1.50,95 \% \mathrm{CI}$ : 1.38 to 1.64 ), severe headache or migraine $(\mathrm{aRRR}=1.80,95 \% \mathrm{CI}: 1.50$ to 2.17). The associations with severe $A D$ showed higher magnitudes for all health conditions, compared with the associations with mild AD. Adjustment for age group, sex, smoking, and education level did not notably change these relationships, and applying the Bonferroni correction did not eliminate the statistical significance of these 
Table 1 Population characteristics by atopic dermatitis diagnosis for 34313 adults (including missing data)

\begin{tabular}{|c|c|c|c|c|}
\hline & & Atopic derma & & \\
\hline & $\begin{array}{l}\text { number in } \\
\text { category } \\
\text { (\% of all in } \\
\text { the study) }\end{array}$ & $\begin{array}{l}\text { No } \\
25955(86.1) \\
\text { n (\%) }\end{array}$ & $\begin{array}{l}\text { Yes, mild } \\
3756(12.5) \\
\text { n (\%) }\end{array}$ & $\begin{array}{l}\text { Yes, severe } \\
419(1.4) \\
\mathrm{n}(\%)\end{array}$ \\
\hline Sex & & & & \\
\hline Male & $15880(46.3)$ & $12033(46.4)$ & $1660(44.2)$ & $151(36.0)$ \\
\hline Female & $18433(53.7)$ & 13922 (53.6) & $2096(55.8)$ & $268(64.0)$ \\
\hline Age & & & & \\
\hline $18-29$ & $5393(15.7)$ & $3991(15.4)$ & $623(16.6)$ & $133(31.7)$ \\
\hline $30-69$ & $15769(46.0)$ & $11921(45.9)$ & $1880(50.1)$ & $175(41.8)$ \\
\hline $70+$ & $13151(38.3)$ & 10043 (38.7) & $1253(33.4)$ & $111(26.5)$ \\
\hline Comorbid conditions & & & & \\
\hline Chronic obstructive lung & & & & \\
\hline No & $22772(96.1)$ & 19217 (96.6) & $2690(95.2)$ & $226(91.5)$ \\
\hline Yes & $912(3.9)$ & $674(3.4)$ & $135(4.8)$ & $21(8.5)$ \\
\hline Asthma & & & & \\
\hline No & $26163(91.7)$ & $22190(92.9)$ & $2993(86.0)$ & $295(77.8)$ \\
\hline Yes & $2368(8.3)$ & $1691(7.1)$ & $486(14.0)$ & $84(22.2)$ \\
\hline Recurrent gastrointestina & & & & \\
\hline No & $22453(73.9)$ & $19680(76.2)$ & $2391(64.6)$ & $205(50.4)$ \\
\hline Yes, mild & $6647(21.9)$ & $5208(20.2)$ & 1105 (29.9) & $131(32.2)$ \\
\hline Yes, severe & $1267(4.2)$ & $936(3.6)$ & $205(5.5)$ & $71(17.4)$ \\
\hline High blood pressure ${ }^{a}$ & & & & \\
\hline No & $16893(66.1)$ & $14245(67.2)$ & $1984(66.0)$ & $152(56.9)$ \\
\hline Yes & $8648(33.9)$ & $6946(32.8)$ & $1020(34.0)$ & $115(43.1)$ \\
\hline Diabetes type $2^{\text {a }}$ & & & & \\
\hline No & $21844(90.2)$ & $18398(90.7)$ & $2604(90.5)$ & $213(83.9)$ \\
\hline Yes & $2383(9.8)$ & $1876(9.3)$ & $274(9.5)$ & $41(16.1)$ \\
\hline Obesity (BMI > = 30) & & & & \\
\hline No & $26764(81.8)$ & 20546 (82.5) & $2818(78.0)$ & $278(71.1)$ \\
\hline Yes & $5970(18.2)$ & $4351(17.5)$ & $795(22.0)$ & $113(28.9)$ \\
\hline Joint pain ${ }^{b}$ & & & & \\
\hline No & $8185(26.9)$ & 7291 (28.5) & $776(21.1)$ & 49 (11.9) \\
\hline Yes, mild & $17539(57.7)$ & $14696(57.4)$ & $2228(60.5)$ & $225(54.5)$ \\
\hline Yes, severe & $4677(15.4)$ & $3638(14.2)$ & $681(18.5)$ & $139(33.7)$ \\
\hline Headache or Migraine & & & & \\
\hline No & $23661(78.7)$ & 20651 (80.3) & $2619(71.7)$ & $244(60.2)$ \\
\hline Yes, mild & $5547(18.5)$ & $4432(17.2)$ & $881(24.1)$ & $122(30.1)$ \\
\hline Yes, severe & $846(2.8)$ & $634(2.5)$ & $153(4.2)$ & $39(9.6)$ \\
\hline Health & & & & \\
\hline WHO-5 Well-being Index & & & & \\
\hline Very Good (WHO5 > 75) & 14804 (48.5) & $12817(50.2)$ & $1483(40.2)$ & $84(20.7)$ \\
\hline Not Very Good & $15750(51.5)$ & 12699 (49.8) & $2204(59.8)$ & $322(79.3)$ \\
\hline How would you rate you & & & & \\
\hline Very Good & 10388 (30.6) & $8292(32.2)$ & $985(26.4)$ & $101(31.3)$ \\
\hline
\end{tabular}


Table 1 Population characteristics by atopic dermatitis diagnosis for 34313 adults (including missing data) (Continued)

\begin{tabular}{|c|c|c|c|c|}
\hline & \multirow{2}{*}{$\begin{array}{l}\text { Total } \\
\text { number in } \\
\text { category } \\
\text { (\% of all in } \\
\text { the study) }\end{array}$} & \multicolumn{3}{|c|}{ Atopic dermatitis } \\
\hline & & $\begin{array}{l}\text { No } \\
25955(86.1) \\
\text { n (\%) }\end{array}$ & $\begin{array}{l}\text { Yes, mild } \\
3756(12.5) \\
\text { n (\%) }\end{array}$ & $\begin{array}{l}\text { Yes, severe } \\
419(1.4) \\
n(\%)\end{array}$ \\
\hline$\overline{\text { Good }}$ & $15349(45.2)$ & $11658(45.2)$ & $1701(45.6)$ & $156(37.4)$ \\
\hline Not Good not Bad & $5404(15.9)$ & $3910(15.2)$ & $672(18.0)$ & $86(20.6)$ \\
\hline Bad & $2113(6.2)$ & $1464(5.7)$ & $295(7.9)$ & $45(10.8)$ \\
\hline Very Bad & $687(2.0)$ & $450(1.7)$ & $77(2.1)$ & $29(7.0)$ \\
\hline \multicolumn{5}{|c|}{ Social and Background Factors } \\
\hline \multicolumn{5}{|l|}{ Smoking } \\
\hline No & $30111(88.9)$ & $23022(89.4)$ & $3298(88.5)$ & $335(80.5)$ \\
\hline Yes (daily or occasionally) & $3777(11.1)$ & $2724(10.6)$ & $427(11.5)$ & $81(19.5)$ \\
\hline \multicolumn{5}{|l|}{ Highest level of education } \\
\hline Compulsory schooling & $8343(24.6)$ & $6090(23.5)$ & $785(21.1)$ & $119(28.8)$ \\
\hline Secondary education & $14688(43.3)$ & $11076(43.1)$ & $1651(44.4)$ & $195(47.2)$ \\
\hline Higher education & $10892(32.1)$ & $8527(33.2)$ & $1281(34.5)$ & $99(24.0)$ \\
\hline
\end{tabular}

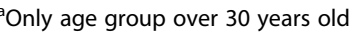

${ }^{\mathrm{b}}$ Pain in one or several of the following: shoulders, neck, back, arms, elbows, legs, knees

results. See Table 2 for detailed information about the relationships between common chronic health conditions and $\mathrm{AD}$.

We re-estimated these associations after stratifying the sample by age and sex. The results were comparable to those of the main analysis, but some of the associations had wider CIs and borderline statistical significance. Adjustment for depression attenuated the magnitude of the associations between $\mathrm{AD}$ and chronic health conditions, but all the associations remained statistically significant.

The analyses of the AD subgroups with and without comorbid asthma showed that the majority of the examined associations were statistically significant for those who had AD but not asthma, however the magnitudes of these associations were lower for this group than for those with comorbid asthma. The exceptions were the associations of $\mathrm{AD}$ with $\mathrm{COPD}$ and with type 2 diabetes, which were statistically significant only in the AD subgroup with comorbid asthma.

\section{Dental comorbidity}

Dental disorders were common in individuals with $\mathrm{AD}$ who were aged 70 years or older (Table 3). Mild AD was significantly associated with caries $(\mathrm{aOR}=1.25,95 \% \mathrm{CI}$ : 1.04 to 1.49$)$, bleeding gums $(\mathrm{aOR}=1.69,95 \% \mathrm{CI}: 1.38$ to 2.08 ), periodontitis ( $\mathrm{aOR}=1.42,95 \% \mathrm{CI}: 1.13$ to 1.77 ), sensitive teeth ( $\mathrm{aOR}=1.57,95 \% \mathrm{CI}: 1.35$ to 1.82$)$, and dry mouth (aOR $=1.52,95 \%$ CI: 1.33 to 1.74$)$. The magnitudes of the associations between severe AD and these dental disorders were even higher, but only the relationships with bleeding gums $(\mathrm{aOR}=2.35,95 \% \mathrm{CI}: 1.27$ to 4.36) and dry mouth (aOR $=2.06,95 \% \mathrm{CI}: 1.34$ to 3.17$)$ were statistically significant. Adjustment for dry mouth slightly reduced the magnitude of all the examined associations between other dental disorders and AD. After additional adjustment for depression, the relationships between $\mathrm{AD}$ and the examined conditions of the oral cavity were attenuated but remained statistically significant except for the relationship between $\mathrm{AD}$ and periodontitis, which became non-significant. After applying the Bonferroni correction associations remained statistically significant, except the $p$-value for the association between caries and mild AD which changed from 0.015 to 0.075 .

\section{Psychological wellbeing}

In the study population, individuals with $\mathrm{AD}$ had a lower odds of having very good psychological wellbeing than did those without $\mathrm{AD}$. Both those with mild $\mathrm{AD}$ and those with severe AD had significantly lower odds of having very good psychological wellbeing, compared with people with diabetes, and this finding showed a dose-dependent relationship (Table 4). There was no difference between individuals with mild $\mathrm{AD}$ and those with diabetes after adjustment. Those with severe AD had a significantly lower odds of having very good psychological wellbeing than did those with diabetes, even after adjustment.

\section{Discussion}

This study demonstrated that adults in Sweden with AD have an increased prevalence of self-reported chronic health conditions such as COPD, asthma, recurrent gastrointestinal symptoms, high blood pressure, obesity, 
Table 2 The associations between atopic dermatitis and study outcomes for 33516 adolescents

\begin{tabular}{|c|c|c|c|c|}
\hline & \multicolumn{2}{|c|}{ Mild atopic dermatitis } & \multicolumn{2}{|c|}{ Severe atopic dermatitis } \\
\hline & $\begin{array}{l}\text { Unadjusted Model } \\
\text { OR/RRR (CI 95\%) }\end{array}$ & $\begin{array}{l}\text { Adjusted Model } \\
\text { aOR/aRRR }^{\mathrm{C}} \text { (Cl 95\%) }\end{array}$ & $\begin{array}{l}\text { Unadjusted Model } \\
\text { OR/RRR (CI 95\%) }\end{array}$ & $\begin{array}{l}\text { Adjusted Model } \\
\text { aOR/aRRR }(\mathrm{Cl} 95 \%)\end{array}$ \\
\hline \multicolumn{5}{|c|}{ Chronic obstructive lung disease $^{a}$} \\
\hline No & Reference & Reference & Reference & Reference \\
\hline Yes & 1.45 (1.20 to 1.76$)$ & 1.58 (1.30 to 1.92$)$ & 2.74 (1.74 to 4.31$)$ & 2.84 (1.77 to 4.57$)$ \\
\hline \multicolumn{5}{|l|}{ Asthma } \\
\hline No & Reference & Reference & Reference & Reference \\
\hline Yes & 2.16 (1.94 to 2.41$)$ & 2.13 (1.91 to 2.38) & 3.87 (3.02 to 4.95$)$ & 3.54 (2.76 to 4.55$)$ \\
\hline \multicolumn{5}{|c|}{ Recurrent gastrointestinal symptoms } \\
\hline No & Reference & Reference & Reference & Reference \\
\hline Yes, mild & 1.75 (1.62 to 1.90$)$ & 1.78 (1.64 to 1.92$)$ & 2.50 (2.00 to 3.12$)$ & 2.48 (1.98 to 3.11$)$ \\
\hline Yes, severe & 1.85 (1.58 to 2.16$)$ & 1.85 (1.58 to 2.17$)$ & 7.38 (5.57 to 9.78) & $6.33(4.74$ to 8.45$)$ \\
\hline \multicolumn{5}{|c|}{ High blood pressure ${ }^{a}$} \\
\hline No & Reference & Reference & Reference & Reference \\
\hline Yes & 1.06 (0.98 to 1.15$)$ & $1.16(1.06$ to 1.26$)$ & 1.57 (1.23 to 2.01$)$ & $1.76(1.36$ to 2.29$)$ \\
\hline \multicolumn{5}{|c|}{ Type 2 diabetes $^{a}$} \\
\hline No & Reference & Reference & Reference & Reference \\
\hline Yes & 1.04 (0.91 to 1.19$)$ & 1.11 (0.97 to 1.28$)$ & 1.82 (1.29 to 2.57$)$ & 1.96 (1.37 to 2.79$)$ \\
\hline \multicolumn{5}{|c|}{ Obesity (BMI > = 30) } \\
\hline No & Reference & Reference & Reference & Reference \\
\hline Yes & 1.34 (1.23 to 1.46$)$ & $1.34(1.23$ to 1.47$)$ & 1.90 (1.52 to 2.37$)$ & 2.01 (1.60 to 2.53 ) \\
\hline \multicolumn{5}{|l|}{ Joint pain ${ }^{\mathrm{b}}$} \\
\hline No & Reference & Reference & Reference & Reference \\
\hline Yes, mild & 1.43 (1.31 to 1.56$)$ & 1.47 (1.35 to 1.61$)$ & 2.35 (1.71 to 3.23$)$ & 2.84 (2.05 to 3.93$)$ \\
\hline Yes, severe & 1.78 (1.60 to 1.99$)$ & 1.91 (1.70 to 2.14$)$ & 6.01 (4.29 to 8.40) & 7.57 (5.34 to 10.73 ) \\
\hline \multicolumn{5}{|c|}{ Headache or Migraine } \\
\hline No & Reference & Reference & Reference & Reference \\
\hline Yes, mild & 1.57 (1.44 to 1.71$)$ & 1.50 (1.38 to 1.64$)$ & 2.33 (1.87 to 2.91$)$ & 1.88 (1.49 to 2.37 ) \\
\hline Yes, severe & $1.92(1.60$ to 2.31$)$ & 1.80 (1.50 to 2.17$)$ & 5.39 (3.81 to 7.63$)$ & 3.89 (2.71 to 5.57$)$ \\
\hline
\end{tabular}

The analyses used logistic regression for binary outcome variables and multinomial regression for categorical outcome variables with more than two categories anly age group over 30 years old

${ }^{b}$ Pain in one or several of the following: shoulders, neck, back, arms, elbows, legs, knees

${ }^{c}$ Adjusted for sex, age group, smoking and education level

joint pain, and headache or migraine. The observed associations show dose-dependent relationships for both $\mathrm{AD}$ severity and the severity of the examined chronic health conditions. We did not observe a statistically significant association between mild $\mathrm{AD}$ and type 2 diabetes; however, those with severe AD had a statistically significantly higher prevalence of type 2 diabetes, compared with those without AD. To the best of our knowledge, this is the first report of a positive association between $\mathrm{AD}$ and conditions of the oral cavity, such as caries, bleeding gums, periodontitis, sensitive teeth, and dry mouth, among older adults. Our findings also showed that $A D$ was associated with decreased general psychological wellbeing, with a magnitude that is at least as high as that for diabetes. The findings also demonstrated that $\mathrm{AD}$ is common in adults, affecting almost $14 \%$ of the adult population in Sweden.

Our study results are in line with previous studies suggesting increased susceptibility to immune-mediated diseases in individuals with $\mathrm{AD}[17,18]$. Schmitt et al. previously reported that individuals with $\mathrm{AD}$ had increased risks of rheumatoid arthritis and inflammatory bowel disease in a large cohort study in Germany [6]. Likewise, the current study found that individuals with $\mathrm{AD}$ have increased odds of joint pain and recurrent gastrointestinal symptoms. Several possible explanations for these findings have been suggested. For example, there may be shared genetic susceptibility loci between 
Table 3 Dental health and association with atopic dermatitis in 10954 people over 70 years old

\begin{tabular}{|c|c|c|c|c|c|c|c|c|}
\hline \multirow{2}{*}{\multicolumn{2}{|c|}{$\begin{array}{l}\text { Total number in } \\
\text { category } \\
\text { (\% of all in the study) }\end{array}$}} & \multicolumn{3}{|c|}{ Atopic dermatitis } & \multicolumn{2}{|c|}{ Mild atopic dermatitis } & \multicolumn{2}{|c|}{ Severe atopic dermatitis } \\
\hline & & $\begin{array}{l}\text { No } \\
10043(88.0) \\
n(\%)\end{array}$ & $\begin{array}{l}\text { Yes, mild } \\
1253(11.0) \\
\text { n (\%) }\end{array}$ & $\begin{array}{l}\text { Yes, } \\
\text { severe } \\
111(1.0) \\
\mathrm{n}(\%)\end{array}$ & $\begin{array}{l}\text { Unadjusted } \\
\text { Model } \\
\text { OR (Cl 95\%) }\end{array}$ & $\begin{array}{l}\text { Adjusted } \\
\text { Model } \\
\mathrm{aOR}^{\mathrm{a}}(\mathrm{Cl} 95 \%)\end{array}$ & $\begin{array}{l}\text { Unadjusted } \\
\text { Model } \\
\text { OR (Cl 95\%) }\end{array}$ & $\begin{array}{l}\text { Adjusted } \\
\text { Model } \\
\mathrm{aOR}^{\mathrm{a}}(\mathrm{Cl} 95 \%)\end{array}$ \\
\hline \multicolumn{9}{|c|}{ Caries } \\
\hline No & $10095(86.6)$ & $8425(87.2)$ & $1002(84.4)$ & $77(81.9)$ & Reference & Reference & Reference & Reference \\
\hline Yes & $1559(13.4)$ & $1233(12.8)$ & $185(15.6)$ & $17(18.1)$ & 1.25 (1.05 to 1.50$)$ & 1.25 (1.04 to 1.49$)$ & 1.52 (0.94 to 2.79$)$ & 1.72 (1.00 to 2.97$)$ \\
\hline \multicolumn{9}{|c|}{ Bleeding gums } \\
\hline No & $10686(92.3)$ & 8955 (93.0) & $1054(88.8)$ & $82(85.4)$ & Reference & Reference & Reference & Reference \\
\hline Yes & $890(7.7)$ & $677(7.0)$ & $133(11.2)$ & $14(14.6)$ & 1.68 (1.37 to 2.07$)$ & 1.69 (1.38 to 2.08$)$ & 2.20 (1.19 to 4.06$)$ & 2.35 (1.27 to 4.36$)$ \\
\hline \multicolumn{9}{|c|}{ Periodontitis } \\
\hline No & $10622(92.4)$ & $8895(93.0)$ & $1062(90.2)$ & $84(86.6)$ & Reference & Reference & Reference & Reference \\
\hline Yes & $871(7.6)$ & $673(7.0)$ & $115(9.8)$ & $13(13.4)$ & 1.44 (1.15 to 1.80$)$ & 1.42 (1.13 to 1.77$)$ & $1.47(0.71$ to 3.06$)$ & 1.41 (0.67 to 2.94 ) \\
\hline \multicolumn{9}{|c|}{ Sensitive teeth } \\
\hline No & $9354(80.8)$ & 7854 (81.6) & $892(75.2)$ & $76(80.9)$ & Reference & Reference & Reference & Reference \\
\hline Yes & 2218 (19.2) & 1766 (18.4) & $294(24.8)$ & $18(19.1)$ & 1.51 (1.31 to 1.75$)$ & 1.57 (1.35 to 1.82$)$ & 1.19 (0.71 to 2.00$)$ & 1.27 (0.75 to 2.16$)$ \\
\hline \multicolumn{9}{|c|}{ Dry mouth } \\
\hline No & $8141(69.0)$ & 6868 (70.6) & $746(62.0)$ & $48(47.5)$ & Reference & Reference & Reference & Reference \\
\hline Yes & 3661 (31.0) & $2865(29.4)$ & $458(38.0)$ & $53(52.5)$ & 1.46 (1.29 to 1.67$)$ & $1.52(1.33$ to 1.74$)$ & 2.20 (1.44 to 3.36$)$ & 2.06 (1.34 to 3.17$)$ \\
\hline
\end{tabular}

${ }^{a}$ Adjusted for sex, age group, smoking, education level and permanent teeth

$\mathrm{AD}$ and autoimmune diseases $[17,19]$. Another potential mechanism is related to prolonged systemic inflammation increasing an individual's risk for developing several autoimmune diseases $[5,17]$. Surveillance bias should be considered in studies investigating comorbidity patterns in individuals with chronic diseases because of the relatively higher health service use in this population.

In the current study, asthma was found to be associated with $\mathrm{AD}$, as expected. Our study is the first to describe the association between COPD and AD. Immunoglobulin E (IgE) sensitization has previously been shown to be more frequent in patients with COPD than in the general population [20]. However, our analysis of AD subgroups with and without comorbid asthma did not confirm a significant association with COPD for those who have $\mathrm{AD}$ without asthma. It is likely that individuals without comorbid asthma had more mild $A D$ and therefore did not show an association with COPD.
Another possibility is misdiagnosis because of the similarity of asthma and COPD symptoms; people who reported COPD might have had asthma instead of COPD or both asthma and COPD.

Several previous studies have aimed to investigate the associations between cardiovascular diseases and $\mathrm{AD}$, with conflicting results $[5,9]$. These differences may be explained by differences in the study designs and diagnostic criteria used in previous studies [21]. Our study findings of relatively high odds of hypertension and type 2 diabetes in individuals with severe $\mathrm{AD}$ are in line with another recent Swedish study [22]. The present study also adds to existing information on the AD-obesity relationship in the Swedish population, especially for those with severe AD. Our findings on this topic are in line with a recent meta-analysis showing an association between AD and obesity in North America and Asia [11]. Among the participants in our study, individuals with

Table 4 Association with WHO5 (very good) comparing atopic dermatitis and diabetes

\begin{tabular}{|c|c|c|c|c|}
\hline & \multicolumn{2}{|l|}{ Unadjusted } & \multicolumn{2}{|l|}{ Adjusted } \\
\hline & OR $(95 \% \mathrm{Cl})$ & $\begin{array}{l}p \text {-value atopic dermatitis } \\
\text { vs. diabetes }\end{array}$ & $\mathrm{aOR}^{\mathrm{b}}(95 \% \mathrm{Cl})$ & $\begin{array}{l}p \text {-value atopic dermatitis } \\
\text { vs. diabetes }\end{array}$ \\
\hline & Reference & Reference & Reference & Reference \\
\hline \multicolumn{5}{|l|}{ Diabetes $^{\mathrm{a}}(n=2542)$} \\
\hline Mild atopic dermatitis ( $n=3$ 182) & 0.84 (0.75 to 0.93 ) & 0.001 & 1.08 (0.96 to 1.21$)$ & 0.181 \\
\hline Severe atopic dermatitis ( $n=332)$ & 0.32 (0.25 to 0.42$)$ & $<0.001$ & 0.48 (0.36 to 0.63$)$ & $<0.001$ \\
\hline
\end{tabular}

${ }^{a}$ All types of diabetes, including those with diabetes and $A D$

${ }^{\mathrm{b}}$ Adjusted for sex, age group, smoking and education level 
severe $A D$ were more frequently smokers than were those with mild $A D$ or without $A D$. It is possible that individuals with severe $\mathrm{AD}$ have a higher prevalence of adverse cardiovascular events because of shared associated factors such as obesity, smoking, hypertension, and diabetes.

Migraine has previously been linked to allergic diseases such as asthma and allergic rhinitis, and some studies have reported an association with $\mathrm{AD}$ in children and adolescents as well [7, 8]. Our study adds new knowledge about the increased prevalence of migraine and headache in adults with AD. The pathophysiology of migraine is still unknown, but the roles of mast cell activation and increased levels of pro-inflammatory cytokines, which may be related to allergic inflammation, have been discussed [23].

Recent work has suggested the suspected involvement of the oral cavity in $\mathrm{AD}$ [24], and several studies have demonstrated poorer dental health in children with $\mathrm{AD}$ compared with those without $\mathrm{AD}[13,25]$. To our knowledge, our study is the first to investigate associations of AD with conditions of the oral cavity, such as caries, bleeding gums, periodontitis, sensitive teeth, and dry mouth, in the older adult population. The underlying mechanisms behind these associations need to be explored in future work. We speculate that the relatively high use of antibiotics and antihistamines in individuals with $\mathrm{AD}$, may affect the microbiome of the oral cavity, inflammation, and dryness of the mouth, may be part of the mechanism for this association. A reduction in the magnitude of the associations of caries, bleeding gums, periodontitis, and sensitive teeth with $\mathrm{AD}$ after adjusting for dry mouth may indicate that dry mouth is part of the explanation for the relationship between $\mathrm{AD}$ and poor dental health.

The associations with psychological wellbeing are consistent with previous work, and our results showed a link between $\mathrm{AD}$ and decreased general psychological wellbeing, especially for those with severe AD [26]. Impaired sleep because of itching and adversely affected selfesteem because of visible disease symptoms may be part of the explanation for this relationship. $\mathrm{AD}$ in late adolescence has been found to be associated with antidepressant medication use in middle age, but the same association for asthma was not statistically significant after adjusting for covariates [27].

\section{Study strengths and limitations}

A strength of our study is its use of a large, randomly selected population sample, which allowed us to perform analyses with $\mathrm{AD}$ subgroups and to investigate relatively uncommon outcomes. The study results consistently showed greater magnitude of associations with the study outcomes for severe AD than for mild AD, demonstrating dose-dependent relationships. These findings suggest that there may be causal relationships between $\mathrm{AD}$ and the examined outcomes. In addition, we were able to adjust for potentially important potential confounding factors such as smoking and education level and to evaluate the effects of comorbid asthma and depression on the study results. Further, we used the Bonferroni correction to correct for the possibility of chance statistically significant findings due to multiple testing. However, despite these statistical approaches, we cannot eliminate the possibility of residual confounding.

Another limitation of our study is the cross-sectional design, which does not allow for evaluation of causality. Our study also had a low response rate. Older people and highly educated people were slightly overrepresented in our study population, which may indicate selection bias. Although adjustment for education level was performed for all analyses, residual confounding because of selection bias cannot be excluded. The nonresponse analysis suggested that our study population is representative of the target population overall. The agestratified analyses showed that the associations did not differ across age groups; thus, the slight overrepresentation of older adults should not have influenced the results. A previously published age-standardized report using the same dataset showed disease prevalence rates that were similar to those previously reported for the adult population in Sweden [14]. Because the data used in this study were self-reported, we cannot exclude the possibility of reporting bias, including recall bias. The data on recurrent gastrointestinal symptoms, joint pain, and headache may refer to several heterogeneous health conditions. The absence of a gold standard for questionnaire-based $\mathrm{AD}$ diagnosis and the fact that respondents may confuse AD with other skin conditions are challenges for questionnaire-based epidemiological studies [21]. A validation study conducted by Silverberg et al. concluded that a self-reported diagnosis of eczema based on a single question ('Have you ever been told by a doctor or other health professional that you had eczema or any kind of skin allergy?') had sufficient validity for the epidemiological study of AD [28]. Another study conducted among adults in Sweden reported that the self-reported lifetime prevalence of atopic dermatitis, assessed by the question 'Have you had childhood eczema?', was $13.7 \%$, which is in line with our findings [29]. Additionally, despite adjusting for smoking in our study, we cannot rule out a residual confounding effect of exposure to smoking on the associations between $\mathrm{AD}$ and health conditions, particularly COPD and periodontitis [10].

\section{Conclusions}

$\mathrm{AD}$ is associated with several common chronic health conditions including conditions of the oral cavity and 
with poor general psychological wellbeing in adults. Individuals with severe $\mathrm{AD}$ and those with comorbid asthma or depression may be especially vulnerable. These findings contribute to the existing information about comorbid conditions among people with AD. Future research should focus on disease mechanisms and optimizing treatment with regard to comorbidity.

\section{Abbreviations}

AD: Atopic dermatitis; COPD: Chronic obstructive pulmonary disease; WHO5: The 5-item World Health Organization Well-Being Index; OR: Odds ratio; aOR: Adjusted odds ratio; RRR: Relative risk ratio; aRRR: Adjusted relative risk ratio; Cl: Confidence interval; BMI: Body mass index

\section{Acknowledgements}

We thank Jennifer Barrett, PhD, from Edanz Group (https://en-author-services. edanzgroup.com/ac) for editing a draft of this manuscript.

\section{Authors' contributions}

All authors (JS, SM, ML, ÅS, and LVK) made substantial contributions to the conception and design of the study. JS and LVK analysed and interpreted the data. JS wrote the first draft of the manuscript. JS, SM, ML, ̊̊s, and LVK contributed to the writing of the manuscript and to revising it critically for important intellectual content. All authors read and approved the final manuscript.

\section{Funding}

JS received a grant for part-time work from the Centre for Clinical Research Värmland County Council, corresponding to $25 \%$ of a full-time equivalent in 2019 to work on the research project. Open Access funding provided by Örebro University.

\section{Availability of data and materials}

The data used in the study contain potentially identifying and sensitive patient information thus, cannot be made publicly available for legal restrictions arising from general data protection regulations and restrictions imposed for ethical approval (registration number: 2015/417). The corresponding author is not allowed to share the data on request. The data are not owned by our research group and a new ethical application would be required to request the data from those responsible.

\section{Ethics approval and consent to participate}

Ethical approval was obtained from the Uppsala Regional Ethics Committee (registration number: 2015/417). Written informed consent was obtained from all participants.

\section{Consent for publication}

Not applicable.

\section{Competing interests}

The authors declare that they have no competing interests.

\section{Author details \\ ${ }^{1}$ School of Medical Sciences, Örebro University, Campus USÖ, S-701 82 Örebro, Sweden. ${ }^{2}$ Department of Dermatology, Karlstad Central Hospital, Karlstad, Sweden. ${ }^{3}$ Clinical Epidemiology Division, Department of Medicine, Karolinska Institute, Stockholm, Sweden. ${ }^{4}$ Department of Epidemiology and Public Health, University College London, London, United Kingdom. ${ }^{5}$ Department of Dermatology, Örebro University Hospital, Örebro, Sweden. ${ }^{6}$ School of Medical Sciences, Lund University, Malmö, Sweden. ${ }^{7}$ Departmen of Occupational and Environmental Dermatology, Skåne University Hospital, Lund University, Malmö, Sweden.}

Received: 15 June 2020 Accepted: 25 November 2020

Published online: 17 December 2020

\section{References}

1. Weidinger S, Novak N. Atopic dermatitis. Lancet. 2016;387(10023):1109-22.
2. Hay RJ, Johns NE, Williams HC, Bolliger IW, Dellavalle RP, Margolis DJ, Marks $R$, Naldi L, Weinstock MA, Wulf SK, et al. The global burden of skin disease in 2010: an analysis of the prevalence and impact of skin conditions. J Invest Dermatol. 2014;134(6):1527-34.

3. Gånemo A, Svensson A, Lindberg M, Wahlgren CF. Quality of life in Swedish children with eczema. Acta Derm Venereol. 2007:87(4):345-9.

4. Theodosiou G, Montgomery S, Metsini A, Dalgard FJ, Svensson A, Kobyletzki LB. Burden of Atopic Dermatitis in Swedish Adults: A Population-based Study. Acta Derm Venereol. 2019;99(11):964-70.

5. Brunner PM, Silverberg JI, Guttman-Yassky E, Paller AS, Kabashima K, Amagai M, Luger TA, Deleuran M, Werfel T, Eyerich K, et al. Increasing Comorbidities Suggest that Atopic Dermatitis Is a Systemic Disorder. J Invest Dermatol. 2017:137(1):18-25.

6. Schmitt J, Schwarz K, Baurecht H, Hotze M, Fölster-Holst R, Rodríguez E, Lee YAE, Franke A, Degenhardt F, Lieb W, et al. Atopic dermatitis is associated with an increased risk for rheumatoid arthritis and inflammatory bowel disease, and a decreased risk for type 1 diabetes. J Allergy Clin Immunol. 2016;137(1):130-6

7. Wei CC, Lin CL, Shen TC, Chen AC. Children with allergic diseases have an increased subsequent risk of migraine upon reaching school age. J Investig Med. 2018;66(7):1064-8.

8. Shreberk-Hassidim R, Hassidim A, Gronovich Y, Dalal A, Molho-Pessach V, Zlotogorski A. Atopic Dermatitis in Israeli Adolescents from 1998 to 2013: Trends in Time and Association with Migraine. Pediatr Dermatol. 2017;34(3): 247-52.

9. Thyssen JP, Halling-Overgaard AS, Andersen YMF, Gislason G, Skov L, Egeberg A. The association with cardiovascular disease and type 2 diabetes in adults with atopic dermatitis: a systematic review and meta-analysis. $\mathrm{Br} J$ Dermatol. 2018;178(6):1272-9.

10. Kantor R, Kim A, Thyssen JP, Silverberg JI. Association of atopic dermatitis with smoking: a systematic review and meta-analysis. J Am Acad Dermatol. 2016;75(6):1119-25.e1.

11. Zhang A, Silverberg II. Association of atopic dermatitis with being overweight and obese: a systematic review and metaanalysis. J Am Acad Dermatol. 2015;72(4):606-16.e4.

12. Bascones-Martínez A, García-García V, Meurman JH, Requena-Caballero L. Immune-mediated diseases: what can be found in the oral cavity? Int J Dermatol. 2015:54(3):258-70.

13. Silverberg Jl, Simpson EL. Association between severe eczema in children and multiple comorbid conditions and increased healthcare utilization. Pediatr Allergy Immunol. 2013;24(5):476-86

14. Von Kobyletzki LB, ed Hälsan i Värmland. Resultat från undersökningen Liv och Hälsa 2017. Karlstad. Universitetstryckeriet Karlstad. ISBN: 978-917867-021-5.

15. Örebro County. (n.d.). Liv \& hälsa 2017. Retrieved November 18, 2020, from https://www.regionorebrolan.se/sv/Halsa-och-vard/Folkhalsa/Folkhalsan-isiffror/Liv-och-halsa-vuxen/Loh_resultat_2017/.

16. Su JC, Kemp AS, Varigos GA, Nolan TM. Atopic eczema: its impact on the family and financial cost. Arch Dis Child. 1997;76(2):159-62

17. Andersen YM, Egeberg A, Gislason GH, Skov L, Thyssen JP. Autoimmune diseases in adults with atopic dermatitis. J Am Acad Dermatol. 2017:76(2): 274-80.e1.

18. Cipriani F, Marzatico A, Ricci G. Autoimmune diseases involving skin and intestinal mucosa are more frequent in adolescents and young adults suffering from atopic dermatitis. J Dermatol. 2017:44(12):1341-8.

19. Paternoster $L$, Standl M, Waage J, Baurecht $H$, Hotze M, Strachan DP, Curtin JA, Bønnelykke K, Tian C, Takahashi A, et al. Multi-ancestry genome-wide association study of 21,000 cases and 95,000 controls identifies new risk loci for atopic dermatitis. Nat Genet. 2015;47(12):1449-56.

20. Neves MC, Neves YC, Mendes CM, Bastos MN, Camelier AA, Queiroz CF, Mendoza BF, Lemos AC. D'Oliveira Junior A. Evaluation of atopy in patients with COPD. J Bras Pneumol. 2013:39(3):296-305.

21. Andersen YMF, Egeberg A, Hamann CR, Skov L, Gislason GH, Skaaby T, Linneberg A, Thyssen JP. Poor agreement in questionnaire-based diagnostic criteria for adult atopic dermatitis is a challenge when examining cardiovascular comorbidity. Allergy. 2018;73(4):923-31.

22. Ivert LU, Johansson EK, Dal H, Lindelöf B, Wahlgren CF, Bradley M. Association Between Atopic Dermatitis and Cardiovascular Disease: A Nationwide Register-based Case-control Study from Sweden. Acta Derm Venereol. 2019:99(10):865-70. 
23. Theoharides TC, Donelan J, Kandere-Grzybowska K, Konstantinidou A. The role of mast cells in migraine pathophysiology. Brain Res Brain Res Rev. 2005;49(1):65-76.

24. Oliveira ADT, Sodré CS, Ferreira DC, Abad ED, Saintive S, Ribeiro M, Cavalcante FS, Piciani B, Gonçalves LS. Oral Aspects Identified in Atopic Dermatitis Patients: A Literature Review. Open Dent J. 2018;12:424-34.

25. Perugia C, Saraceno R, Ventura A, Lorè B, Chiaramonte C, Docimo R, Chimenti S. Atopic dermatitis and dental manifestations. G Ital Dermatol Venereol. 2017;152(2):122-5.

26. Cheng BT, Silverberg JI. Depression and psychological distress in US adults with atopic dermatitis. Ann Allergy Asthma Immunol. 2019;123(2):179-85.

27. Sato Y, Hiyoshi A, Melinder C, Suzuki C, Montgomery S. Asthma and Atopic Diseases in Adolescence and Antidepressant Medication in Middle Age. J Health Psychol. 2018;23(6):853-9.

28. Silverberg II, Patel N, Immaneni S, Rusniak B, Silverberg NB, Debashis R, Fewkes N, Simpson EL. Assessment of atopic dermatitis using self-report and caregiver report: a multicentre validation study. Br J Dermatol. 2015; 173(6):1400-4.

29. Bingefors K, Svensson Å, Isacson D, Lindberg M. Self-reported lifetime prevalence of atopic dermatitis and co-morbidity with asthma and eczema in adulthood: a population-based cross-sectional survey. Acta Derm Venereol. 2013;93(4):438-41.

\section{Publisher's Note}

Springer Nature remains neutral with regard to jurisdictional claims in published maps and institutional affiliations.

Ready to submit your research? Choose BMC and benefit from:

- fast, convenient online submission

- thorough peer review by experienced researchers in your field

- rapid publication on acceptance

- support for research data, including large and complex data types

- gold Open Access which fosters wider collaboration and increased citations

- maximum visibility for your research: over $100 \mathrm{M}$ website views per year

At BMC, research is always in progress.

Learn more biomedcentral.com/submissions 